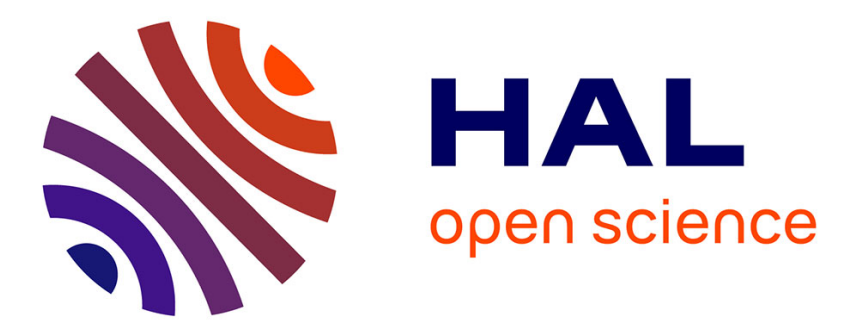

\title{
Chemometrics as a tool for the analysis of evolved gas during the thermal treatment of sewage sludge using coupled TG-FTIR
}

\author{
J.H. Ferrasse, Patricia Arlabosse, S. Chavez, N. Dupuy
}

\section{To cite this version:}

J.H. Ferrasse, Patricia Arlabosse, S. Chavez, N. Dupuy. Chemometrics as a tool for the analysis of evolved gas during the thermal treatment of sewage sludge using coupled TG-FTIR. Thermochimica Acta, 2003, 404 (1-2), pp.97-108. 10.1016/S0040-6031(03)00064-9 . hal-00275348

\author{
HAL Id: hal-00275348 \\ https://hal.science/hal-00275348
}

Submitted on 19 Dec 2017

HAL is a multi-disciplinary open access archive for the deposit and dissemination of scientific research documents, whether they are published or not. The documents may come from teaching and research institutions in France or abroad, or from public or private research centers.
L'archive ouverte pluridisciplinaire HAL, est destinée au dépôt et à la diffusion de documents scientifiques de niveau recherche, publiés ou non, émanant des établissements d'enseignement et de recherche français ou étrangers, des laboratoires publics ou privés. 


\title{
Chemometrics as a tool for the analysis of evolved gas during the thermal treatment of sewage sludge using coupled TG-FTIR
}

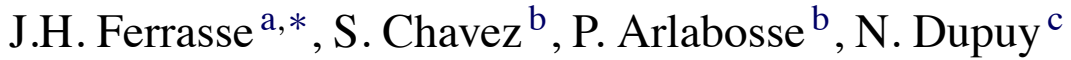 \\ a IUT de Marseille, Département de Génie Chimique-Génie des Procédés, Université Aix, Marseille 3, 13388 Marseille Cedex, France \\ b Centre Energétique Environment, Laboratoire de Génie des Procédés des Solides Divisés, (CNRS-UMR 2392)-Ecole des Mines \\ d'Albi-Carmaux-Route de Teillet, 81013 Albi CT Cedex 09, France \\ c Laboratoire de Spectroscopie Infrarouge et Raman (LASIR), CNRS, Bât C5, Université des Sciences et Technologies de Lille, \\ 59655 Villeneuve d'Ascq Cedex, France
}

\begin{abstract}
The thermal decomposition of sewage sludge has been investigated using coupled TG-FTIR for long time experiment $(10 \mathrm{~h})$. The exploitation of the resulted data from FTIR is performed by the SIMPLe-to-use interactive self-modelling mixture analysis (SIMPLISMA) method and allows to identify some of the evolved gases and to obtain their relative concentration profiles versus time without prior knowledge of constituents. As shown, this method can work properly for mixture with overlapped bands but some compounds remain "invisible" to FTIR analysis. More of that for long time experiment, it is possible to extract a spectrometer baseline contribution, which contributes to minimise noise and time variation.
\end{abstract}

Keywords: EGA; Mixture; Chemometric; TGA; FTIR; Sewage sludge

\section{Introduction}

Today, the municipal sewage sludge production represents in France close to 1 million tonnes per year of dry matter, the amount of dry matter produced in Europe is estimated to be 7.7 million tonnes [1]. The stabilisation and disposal of these waste has become a problem of increasing urgency because of more restrictive regulation of wastewater treatment, that will inevitably induce an increase in the production of sewage sludge. Thus, the sludge production in the EU is expected to increase by least at $50 \%$ by the year 2005 [2]. The thermal treatment may be con-

\footnotetext{
* Corresponding author. Tel.: +33-4-92-289462. E-mail address: jean-henry.ferrasse@univ.u-3mrs.fr (J.H. Ferrasse).
}

sidered like an interesting route to deal with those waste.

In environmental analysis, many TA techniques have been applied to study thermal degradation of waste. For instance, Napoli used TG-DSC to analyze the degradation of refuse tires [3] and Lupascu investigated the thermal characteristics of some waste agriculture products which can serve as raw materials for the production of active carbons (grape seeds, walnut shells ... ) [4]. Font studied the pyrolysis and combustion of some sewage sludges [5]. But, as the kinetics are generally complex, the elucidation of the degradation mechanisms from the knowledge of the mass variation without precise formulae for the intermediate compounds, remain rather complex.

Evolved gas analysis (EGA) is a recent and useful tool for the investigation of thermal decomposition 
mechanisms as, in addition to the mass loss of the heated product, information about the evolution of the evolved substances are available. Among several techniques, coupling a TG with infrared spectroscopy appears to be more and more common [6-11]. One major advantage of this coupling is to be a non-destructive method. Raafat uses this technique to investigate combustion process of fibrous sludge [12]. However, the compounds identification remains uneasy due to mixtures. The gaseous compounds are removed by the gas carrier of the TG apparatus through a heated transfer line to the FTIR spectrometer. Thus, the spectra obtained are the spectra of mixtures of specific individual compounds (at least the more concentrated ones). For the less concentrated ones the interpretation may be difficult according to the overlapping bands especially in the water vapour region. The purpose of the present study is to identify the volatile organic components likely to be exhausted during a thermal treatment which is time dependant. The technique belongs to the self-modelling mixture analysis methods and is called SIMPLe-to-use interactive self-modelling mixture analysis, SIMPLISMA [13]. It leads to the extraction of pure component spectra that contain intensity contributions from only one of the components in the mixture, with their relative concentration profiles as a function of time in our study.

The sewage sludge used in the present study as well as the TG-FTIR coupling and the operating conditions are detailed in Section 2. The SIMPLISMA method is briefly presented in Section 3. Section 4 concerns the results.

\section{Product and materials}

\subsection{Municipal sewage sludge}

Municipal sewage sludge is a complex waste whose composition and physical features depend on the wastewater composition and the sludge treatment process used. It usually contains, alter mechanical dewatering, some $80 \%$ of water, $10-15 \%$ of organic compounds and $5-10 \%$ of mineral compounds.

The sewage sludge used for this study comes from the treatment plant of the town of Albi, France. The average total throughput in the plant is close to $10,000 \mathrm{~m}^{3}$ a day. In comparison with the most common treat-
Table 1

Elementary composition of dry sewage sludge from Albi

\begin{tabular}{ll}
\hline & Dry matter (\%) \\
\hline Carbon & 36 \\
Nitrogen & 5.5 \\
Hydrogen & 5.27 \\
Oxygen & 24.5 \\
Sulfur & Undetected \\
\hline
\end{tabular}

ment plants in France, this sewage treatment process presents a distinctive feature: a methanation process ends the sludge treatment [14]. It is based on a biological stabilisation in a liquid phase by using the mesophilic anaerobic technique. The volatile fraction of the dry matter is $69 \%$, and the elementary composition of the dry sludge is summarised in Table 1 .

Before thermal analysis, the sewage sludge was pre-dried at $20^{\circ} \mathrm{C}$ during $24 \mathrm{~h}$ in a drying oven in order to reduce water content to $0.1 \mathrm{~kg}$ of water $/ \mathrm{kg}$ of dry matter.

\subsection{The $T G$}

Thermogravimetry (TG) was performed with a Setaram TGA $92[15,16]$. The sample is introduced in two platinum pans of $100 \mu \mathrm{l}$ volume (using DTA facilities, but DTA is not recorded), which give an initial mass of sludge close to $125 \mathrm{mg}$. The pans undergo the following temperature program:

- a constant temperature at $20^{\circ} \mathrm{C}$ during $10 \mathrm{~min}$;

- a temperature increase up to $120^{\circ} \mathrm{C}$ with $5 \mathrm{~K} / \mathrm{min}$;

- a constant temperature for $5 \mathrm{~h}$ at $120^{\circ} \mathrm{C}$;

- a new temperature ramp up to $350^{\circ} \mathrm{C}$ with $10 \mathrm{~K} / \mathrm{min}$;

- an isotherm of $5 \mathrm{~h}$ at $350{ }^{\circ} \mathrm{C}$.

This unusual temperature profile is used to be the closest to an industrial thermal treatment planned.

\subsection{FTIR}

IR measurements were performed with a PerkinElmer FTIR 2000, using a $\mathrm{KBr}$ cell maintained at $200{ }^{\circ} \mathrm{C}$. The measurement cell is continuously purged with nitrogen. The resolution was $2 \mathrm{~cm}^{-1}$ with two accumulations per spectra. The interval between two measurements is equal to $14.6 \mathrm{~s}$. 


\subsection{The TG-FTIR coupling}

A heated line furnished by Perkin-Elmer makes the physical coupling between the thermal analyser and the spectrometer. This line is maintained at a temperature of $200{ }^{\circ} \mathrm{C}$. All care must be taken to avoid cold points. A Teflon liner assures gas transport into the heated line. This liner is placed directly in the bottom of the furnace and temperature is close to $200^{\circ} \mathrm{C}$ (a map of temperatures of the furnace was previously generated with a thermocouple).

Air, previously purged with a Whatman purifier, was used as sweeping gas. The flow rate was close to $1.75 \mathrm{l} / \mathrm{h}$. Delay time from furnace to gas cell is estimated to be close to 10 min using plug flow approach.

\section{SIMPLISMA approach}

The method used for self-modelling analysis is the SIMPLISMA approach [13]. The great advantage of this method resides in the fact that it uses a relatively simple algorithm. All the intermediate steps are displayed in the form of spectra that makes SIMPLISMA usable without extensive knowledge of the calculation procedures behind it. The mathematical principle of SIMPLISMA is based on the presence of pure variables. In spectroscopic terms, a pure variable (e.g. a wavelength for absorption electronic spectra) is a variable that has intensity contribution from only one of the components of the mixture. When the pure variables of all the components are known, it is possible to calculate the spectra of the pure components from the mixture spectra. The pure variables can be determined by mathematical means without prior knowledge of the pure components (see Appendix A). SIMPLISMA is then a powerful tool to determine the pure variables followed by the calculation of the pure spectra and their associated "contributions".

Some applications of SIMPLISMA have already been reported in the literature on FT-Raman spectra of hydrogen peroxide activation by nitriles time-resolved reaction [18], FT-IR microscopy spectra of polymer laminate and pyrolysis mass spectra of biomaterials (feedstock) $[19,20]$ and for LC/MS data [20]. For more information, Gemperline and Hamilton $[21,22]$ wrote complete articles about factor analysis based on mixture analysis, and for a more geometrically oriented explanation, see the review of Windig [23] about mixture analysis by multivariate methods.

In order to obtain proper resolution of the mixture data, user interaction is possible. This requirement is a plus in order to deal properly with features such as noise, peak shift and instrument drift [24]. In this study, only the offset was modified (see Appendix A for the meaning of this parameter).

\section{Results and discussion}

From an experimental test, we obtain a TG curve and an FTIR data set composed of 2646 infrared spectra. The information content in this data is considerable, and thus the exploitation is difficult and memory problems occurs for computers. That is why we decide to divide the whole data set into several zones.

Fig. 1 presents the mass loss of the studied sewage sludge as a function of time (TG curve) and the evolution of the sludge temperature using DTA facilities from the apparatus.

The variations in the slope of TG curve express the evolution of sludge degradation rate. Following these variations, the whole data set are divided into five zones:

- zone I: between 0 and $26 \mathrm{~min}$, spectra from 41 to 146 (the spectra numbered 1-40 are not included in this analysis because they correspond to the delay time between the furnace and gas cell);

- zone II: between 26 and $327 \mathrm{~min}$, spectra from 146 to 1386 ;

- zone III: between 327 and $348 \mathrm{~min}$, spectra from 1386 to 1471 ;

- zone IV: between 348 and $470 \mathrm{~min}$, spectra from 1471 to 1975 ;

- zone $V$ : between 470 and $643 \mathrm{~min}$, spectra from 1975 to 2646.

Fig. 2 presents a spectrum of each zone described above. As we can see, intensities of the water vapour and the carbon dioxide spectra prevent the identification of other compounds on the raw data set.

\subsection{Zone I}

This zone corresponds to the first temperature climb from 20 to $120^{\circ} \mathrm{C}$. The 105 spectra of this zone were 


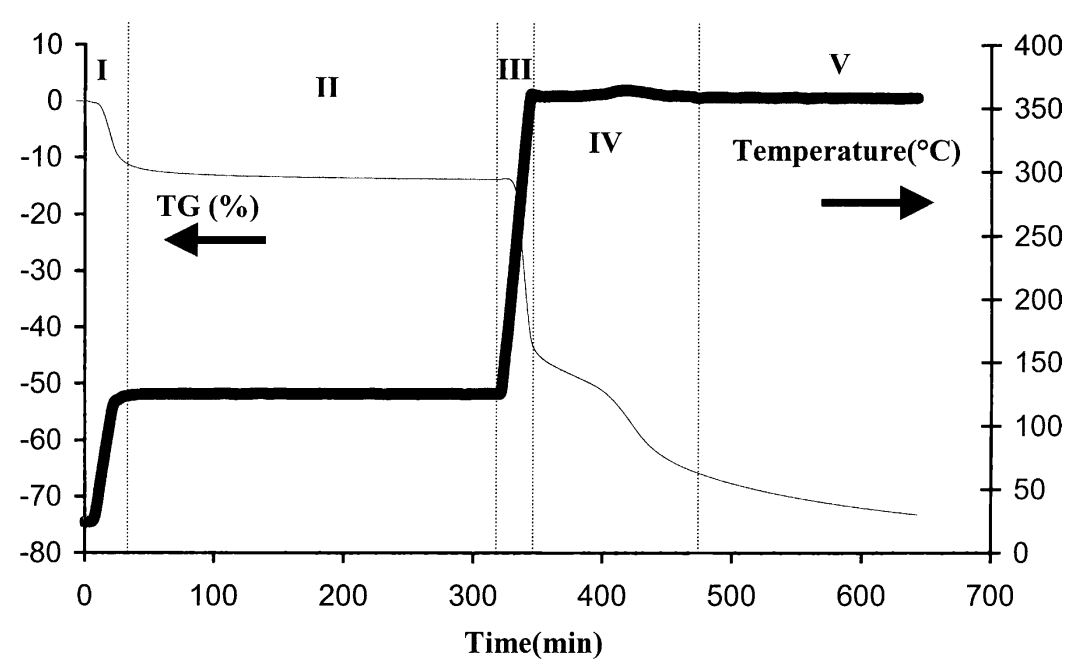

Fig. 1. TG curve and temperature profile of the experiment as a function of time.

treated using the SIMPLISMA procedure with an offset equal to 4 (see Appendix A for the meaning of this offset). This analysis yields two typical spectra corresponding to water and carbon dioxide traces. The resolved spectra and their relative contributions are shown in Fig. 3. As a matter of fact, the relative concentration profiles show that water was the prevailing component and its highly concentration explained the difficulty to obtain a good extraction of the water spectra. Some residues of its rotational structure were observed on the $\mathrm{CO}_{2}$ spectra. The difference of purge time between the reference spectrum $(5 \mathrm{~min})$ and the sample one could explain the negative value of the relative concentration (10-20 $\mathrm{min})$. When the concentrations of the compound are very small, negative concentrations are founded because the infrared cell contained more water and $\mathrm{CO}_{2}$ in the reference time than in the sample one. This zone exactly corresponds to the first increase of temperature from 25 to $120^{\circ}$. The mass loss corresponds to $10 \%$ of the initial mass, and we may conclude that this is essentially drying.

\subsection{Zone II}

This zone corresponds to the first temperature stage at $120^{\circ} \mathrm{C}$. The SIMPLISMA analysis performed on

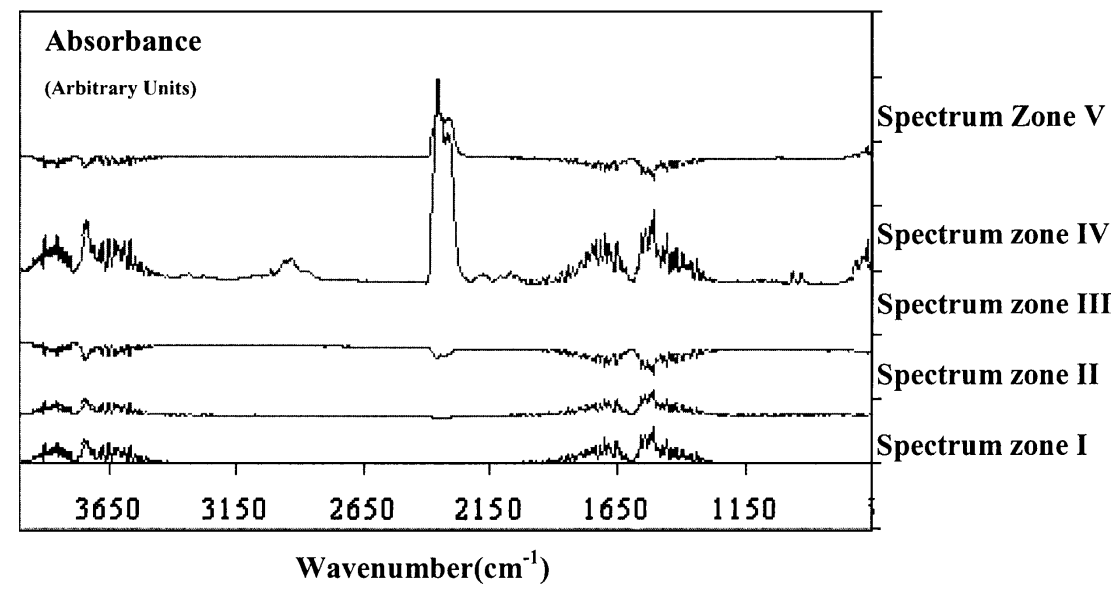

Fig. 2. Example of a instantaneous spectrum of the mixture for each selected zone. 

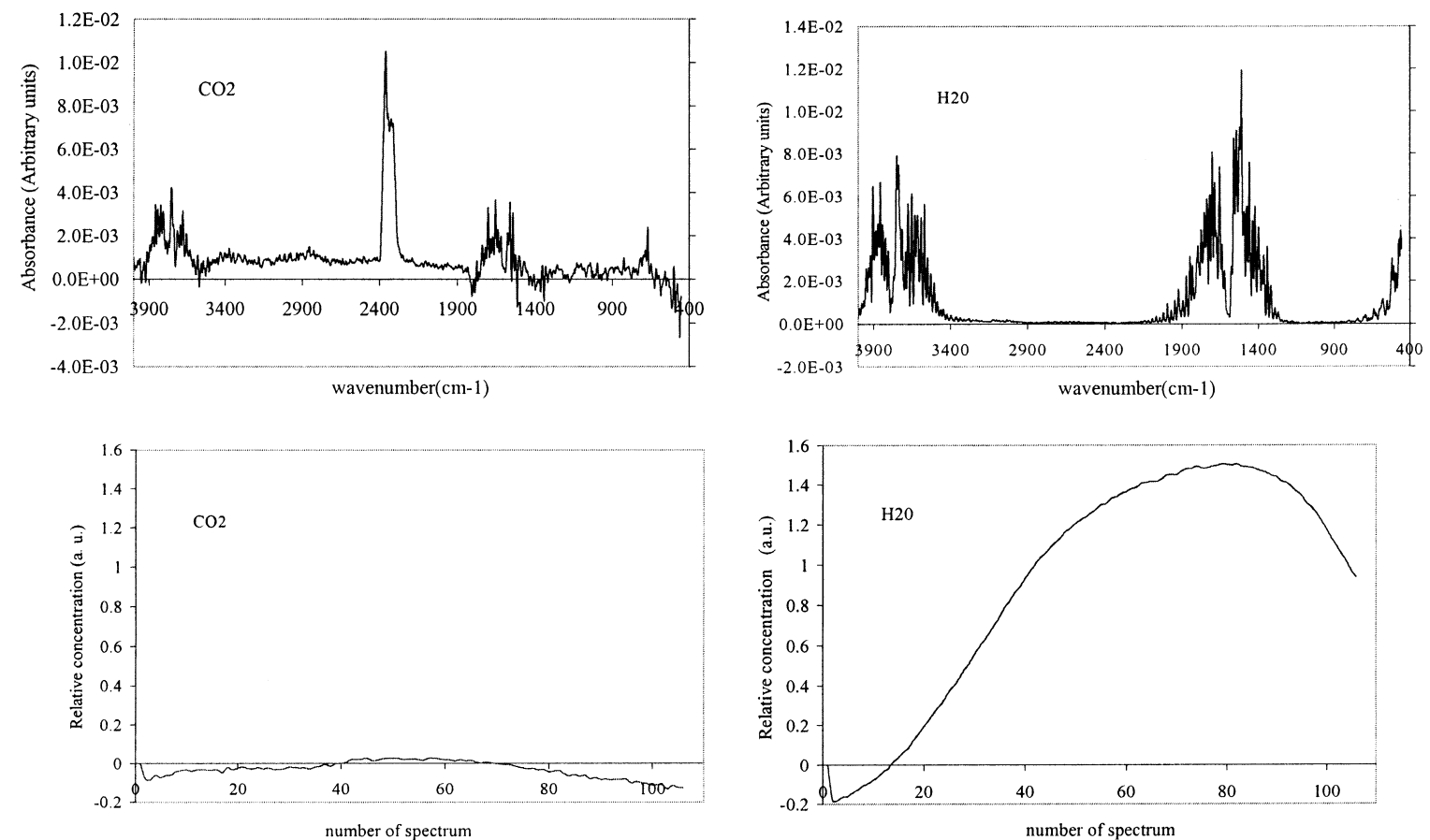

Fig. 3. Resolved spectra and relative contributions from zone I. 
1240 absorbance spectra (offset $=15$ ) shows that four components could be extracted: spectrometer contribution, water, carbon dioxide and ammonia (water residues are observed in $\mathrm{CO}_{2}$ and $\mathrm{NH}_{3}$ spectra). The spectrometer contribution was normal from a spectroscopic point of view. As a matter of fact, the spectrometer caused time variations according to the room temperature, the source energy, etc. So if the analysis is time consuming, the reference spectrum is not sufficient to eliminate some spectral variations. Consequently a contribution named "baseline or spectrometer contribution" is extracted, considering a wavelength equal to $4000 \mathrm{~cm}^{-1}$. The departure of water, which corresponded to the end of drying, appeared at the first plateau. Then, the relative concentration attributed to water became very weak, like those of carbon dioxide. During this stage, the mass loss is close to $0.6 \%$ of the initial mass and it seems to come only from $\mathrm{NH}_{3}$ production as can be seen in Fig. 4. The oscillations in the concentration profiles can be related to a difference in the purge system, in particular to the compressor pump period.

\subsection{Zone III}

This is a short transition zone that corresponds to the second temperature climb from 120 to $350^{\circ} \mathrm{C}$. Only three components could be extracted using SIMPLISMA (offset $=15$ ): spectrometer contribution, water and $\mathrm{CO}_{2}$. The relative concentrations of water and $\mathrm{CO}_{2}$ (Fig. 5) are negatives at the beginning of this stage according to the spectra which presented negatives absorbance. From $334 \mathrm{~min}$, the relative concentration of $\mathrm{CO}_{2}$ increases weakly and simultaneously the mass loss on the TG curve starts to decrease again.

At the end of this zone, approximately $30 \%$ of the initial mass of sludge was consumed. The temperature of sludge at the same moment $\left(280^{\circ} \mathrm{C}\right)$ corresponds to the minimum level of energy to trigger off the reaction. Indeed, only the presence $\mathrm{CO}_{2}$ was detected by FTIR but we can suppose that some other gases such as $\mathrm{H}_{2}, \mathrm{O}_{2}$, etc. which are inactive in infrared, are simultaneously produced [25].

\subsection{Zone IV}

In order to identify all the gases during this step, the SIMPLISMA approach was performed on 504 spec- tra with an offset equal to 4 . Twelve spectral contributions were extracted corresponding to pure variables at 2364, 1508, 964, 4000, 2936, 2072, 1060, $1740,712,1800,2180$ and $3016 \mathrm{~cm}^{-1}$. These variables were respectively attributed to carbon dioxide, water, ammonia, spectrometer contribution, ethane, carbonyl sulfide, methanol, unknown organic product, hydrogen cyanide, acetic acid, carbon monoxide and methane. The products were identified according to the Shimanouchi interpretation [26] or by comparison with the spectra ones of the NIST standard reference database [27]. The pure variable extracted at $4000 \mathrm{~cm}^{-1}$ is a representation of the spectrometer contribution identified by SIMPLISMA as a pure product. Instead of showing all the spectra, pure variables and associated peaks are compared to literature value in Table 2.

The concentration profiles (Fig. 6) associated to the SIMPLISMA pure components show that some species, such as $\mathrm{NH}_{3}, \mathrm{CH}_{4}, \mathrm{C}_{2} \mathrm{H}_{6}$ and $\mathrm{CH}_{3} \mathrm{OH}$, are strongly found at the beginning of the process, while others like $\mathrm{H}_{2} \mathrm{O}, \mathrm{CO}_{2}$ are produced all the time with different concentration ratios. These concentration profiles show the existence of two peaks of maximal concentration of the compound. The first one appears at $372 \mathrm{~min}$ (close to 107 on abscissa ordinate) and is generally the most intense. The second one appears close to $461 \mathrm{~min}$ (470 on the abscissa ordinate) and the intensity may be variable according to the component.

During this stage, a thermal effect (disturbing sample temperature measurement) is register too (at $419 \mathrm{~min}$ ), as well as a total mass loss of $21.4 \%$, shown on Fig. 1. However, this mass loss is fickle and an acceleration of the sludge degradation rate is registered at $439 \mathrm{~min}$.

Beside this, water and dioxide carbon are synonymous with combustion. Combustion is an exothermic oxidation reaction of organic matter, which needs a minimal thermal contribution to produce water, carbon dioxide and some by-products (according to the experimental conditions). Carbon monoxide is a by-product of combustion produced under sub-stoichiometric conditions or when the temperature is not high enough to lead the instantaneous oxidation of $\mathrm{CO}$ into $\mathrm{CO}_{2}$. Some of those by-products (methane, alcohol, acetic acid) have been also identified in sludge pyrolysis (a thermal treatment in sub-stoichiometric conditions) by Conesa [25] with a TG-MS coupling. 

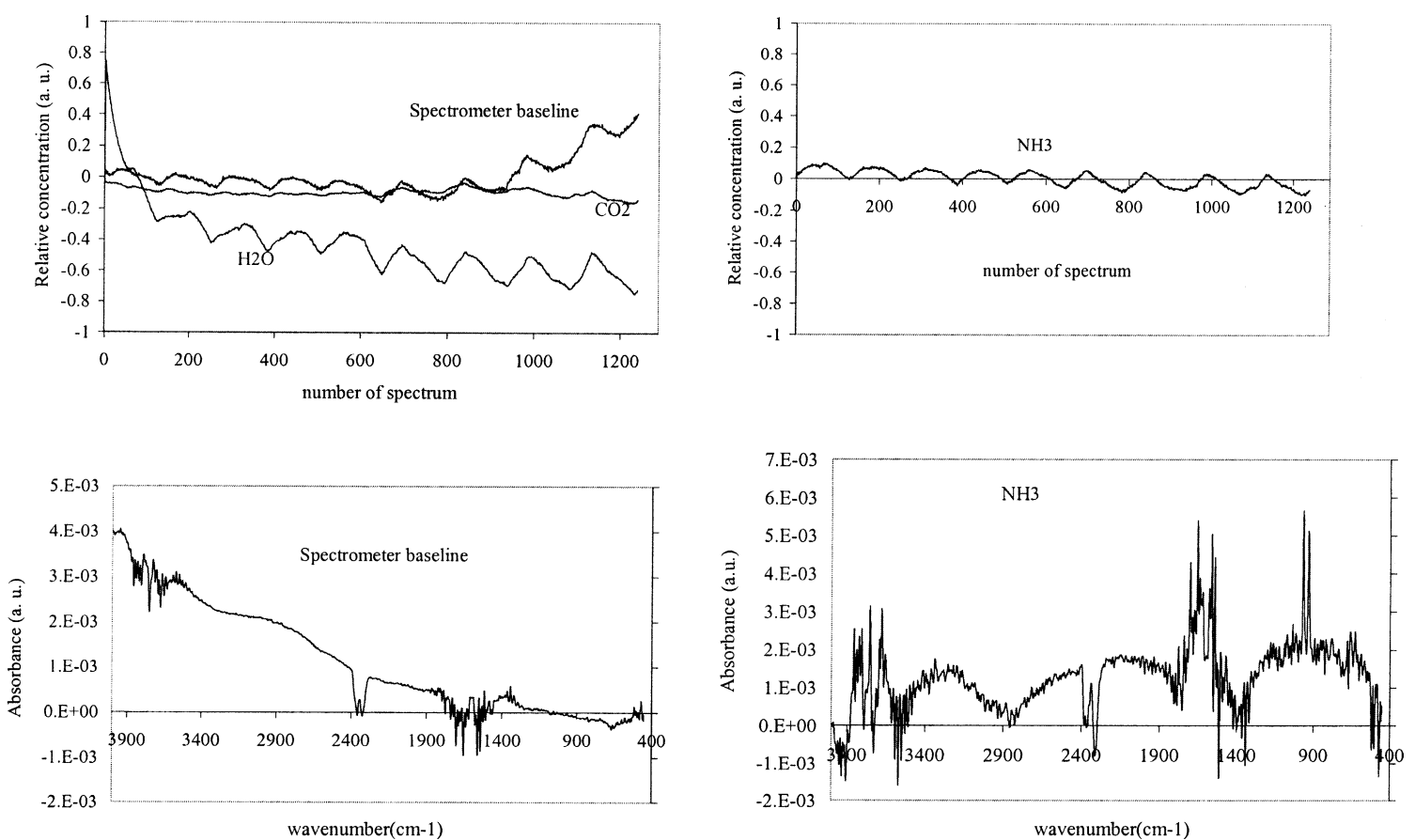

Fig. 4. Resolved spectra and relative concentration profiles from zone II. 

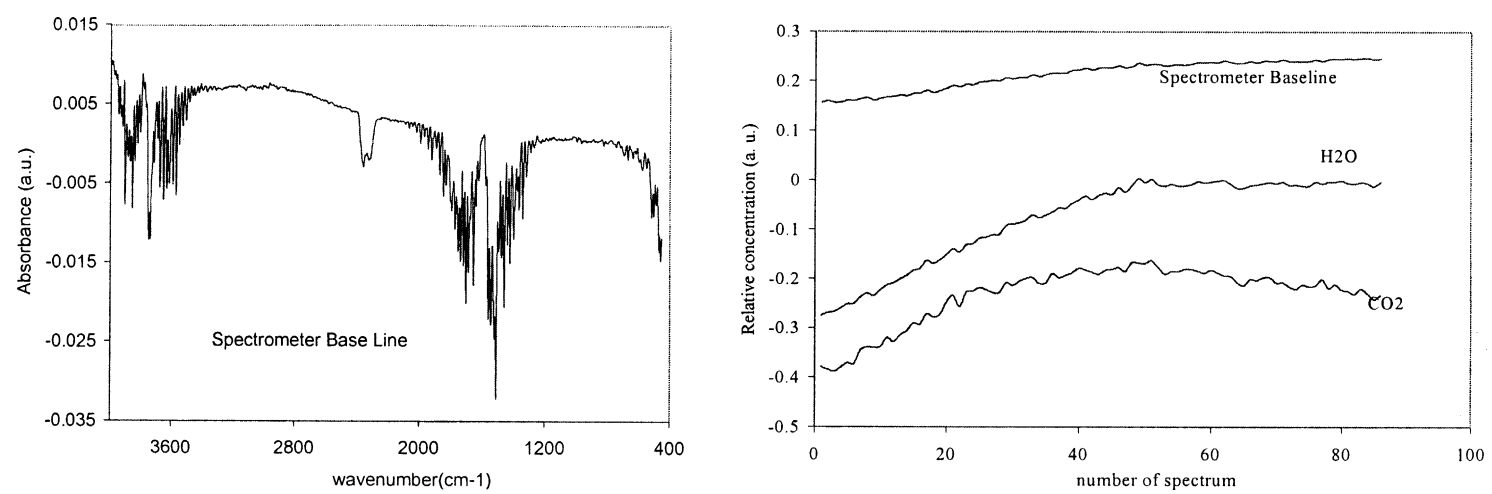

Fig. 5. Relative contribution profiles from zone III. 
Table 2

Comparison between the extracted pure spectra and the literature data

\begin{tabular}{|c|c|c|c|c|c|c|c|c|c|c|c|c|}
\hline & \multicolumn{12}{|c|}{ Pure variable } \\
\hline & \multicolumn{2}{|c|}{$2364 \mathrm{~cm}^{-1}$} & \multicolumn{2}{|c|}{$1508 \mathrm{~cm}^{-1}$} & \multicolumn{2}{|c|}{$964 \mathrm{~cm}^{-1}$} & \multicolumn{2}{|c|}{$4000 \mathrm{~cm}^{-1}$} & \multicolumn{2}{|c|}{$2936 \mathrm{~cm}^{-1}$} & \multicolumn{2}{|c|}{$2072 \mathrm{~cm}^{-1}$} \\
\hline & Exp. & Lit. & Exp. & Lit. & Exp. & Lit. & Exp. & & Exp. & Lit. & Exp. & Lit. \\
\hline & 672 & 671 & 1600 & 1595 & 948 & 943 & & & 2968 & & 2064 & 2063 \\
\hline & $\mathrm{P}$ & $\mathrm{P}$ & $\mathrm{P}$ & $\mathrm{P}$ & $\mathrm{P}$ & $\mathrm{P}$ & & & $\mathrm{P}$ & 2900 & D & D \\
\hline & 2352 & 2360 & 3237 & 3745 & & & & & 2868 & 1462,829 & & \\
\hline & D & D & $\mathrm{P}$ & $\mathrm{P}$ & 1620 & 1626 & BASEI & & ND & & & \\
\hline & 3668 & 3662 & & & & & & & & & & \\
\hline & FB & FB & & & 3328 & 3326 & DRIFT & & & & & \\
\hline \multirow[t]{11}{*}{ Product } & \multicolumn{2}{|l|}{$\mathrm{CO}_{2}$} & \multicolumn{2}{|l|}{$\mathrm{H}_{2} \mathrm{O}$} & \multicolumn{2}{|l|}{$\mathrm{NH}_{3}$} & & & \multicolumn{2}{|l|}{$\mathrm{C}_{2} \mathrm{H}_{6}$} & \multicolumn{2}{|l|}{ COS } \\
\hline & \multicolumn{2}{|c|}{$1060 \mathrm{~cm}^{-1}$} & \multicolumn{2}{|c|}{$1740 \mathrm{~cm}^{-1}$} & \multicolumn{2}{|c|}{$712 \mathrm{~cm}^{-1}$} & \multicolumn{2}{|c|}{$1800 \mathrm{~cm}^{-1}$} & \multicolumn{2}{|c|}{$2180 \mathrm{~cm}^{-1}$} & \multicolumn{2}{|c|}{$3016 \mathrm{~cm}^{-1}$} \\
\hline & 1032 & 1033 & & & 712 & 712 & & & 2140 & 2145 & 3016 & 3017 \\
\hline & TB & TB & 1144 & & $\mathrm{P}$ & $\mathrm{P}$ & 980 & 988 & D & D & $\mathrm{P}$ & $\mathrm{P}$ \\
\hline & & 1345 & & & 3308 & 3311 & & & & & & 1304 \\
\hline & & ND & & & $\mathrm{D}$ & $\mathrm{D}$ & 1176 & 1177 & & & & ND \\
\hline & 2960 & 2960 & & & & 2096 & & & & & & \\
\hline & $\mathrm{P}$ & $\mathrm{P}$ & 1564 & & & ND & 1276 & 1280 & & & & \\
\hline & 3680 & 3680 & 1740 & & & & 1392 & 1392 & & & & \\
\hline & & & & & & & 1792 & 1799 & & & & \\
\hline & & & & & & & $\mathrm{D}$ & $\mathrm{D}$ & & & & \\
\hline Product & $\mathrm{CH}_{3} \mathrm{C}$ & & Unknc & & $\mathrm{HCN}$ & & $\mathrm{CH}_{3} \mathrm{CC}$ & & $\mathrm{CO}$ & & $\mathrm{CH}_{4}$ & \\
\hline
\end{tabular}

P stands for pattern, D for doublet, TB for three bands, FB for four bands, ND for non-detected.

Indeed, at the beginning of this stage, we observe the combustion of sludge, associated with some other reactions that will simultaneously produce the whole of the components identified. These transformations will consume around $4 \%$ of the initial mass of sludge with a maximum on the reaction rates at 373 min. Probably, the heat produced during combustion increase the sludge temperature and induces the acceleration of the
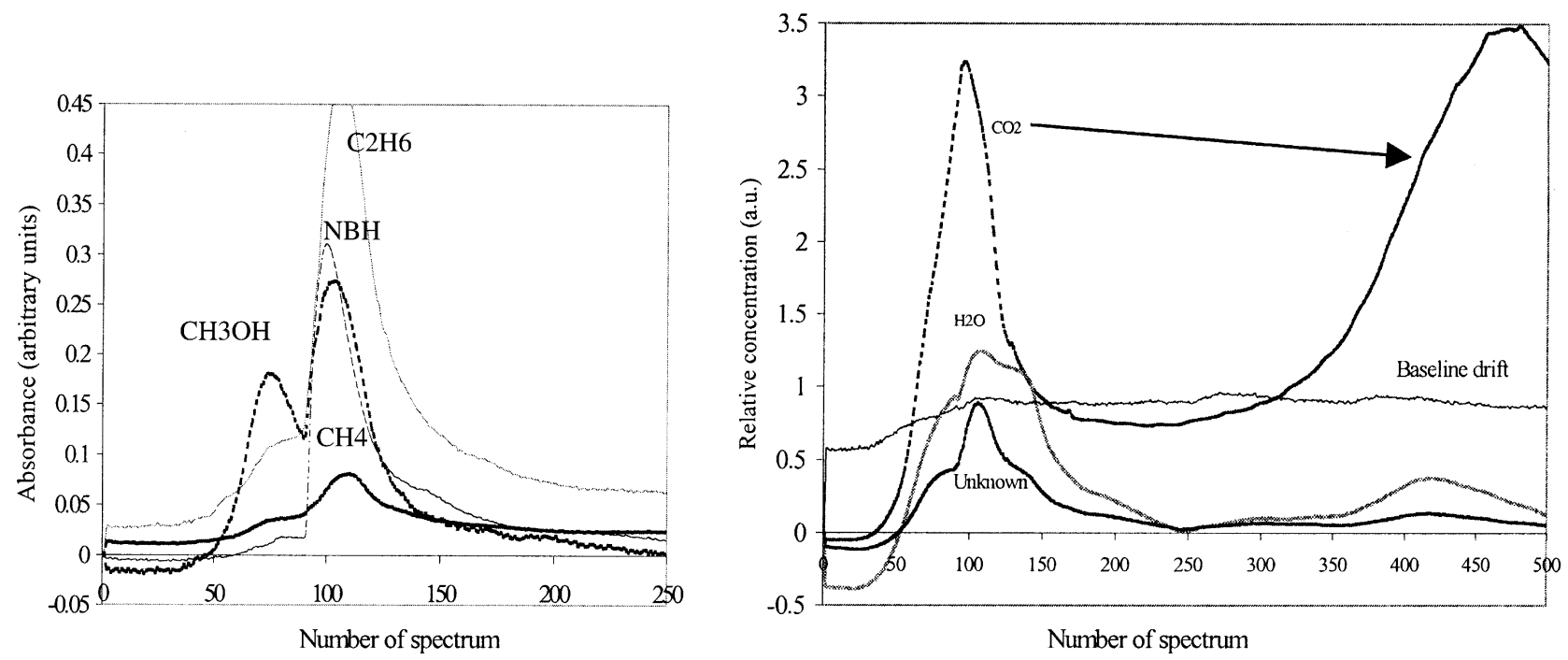

Fig. 6. Relative contribution profiles from zone IV. 
reaction rates. As a consequence, a variation on the slope of the TG curve and the appearance of the second peak on the relative concentration of $\mathrm{CO}, \mathrm{H}_{2} \mathrm{O}$, $\mathrm{CO}_{2}$ is registered. This zone emphasises the helpful tool. Indeed, the peak's identification done here has to be compared to the apparent spectra of zone IV shown in Fig. 2.

\subsection{Zone $V$}

This is the end of the stage at $350^{\circ}$. The SIMPLISMA approach was performed with an offset of 28 . $\mathrm{H}_{2} \mathrm{O}, \mathrm{CO}_{2}$, spectrometer contribution, $\mathrm{HCN}, \mathrm{CO}$ and $\mathrm{NH}_{3}$ were found. Relative concentration profiles show a decreasing slope that can be linked to the TG curves. This one does not show a stabilisation of the mass. This stage corresponds to the end of the combustion. This tends prove that even in slow combustion rate, the exhausted gas obtained are not only composed by $\mathrm{CO}_{2}$ and $\mathrm{H}_{2} \mathrm{O}$ but also of some pollutants as $\mathrm{CO}, \mathrm{NH}_{3}$, $\mathrm{HCN}$.

At the end of this treatment, the loss of mass calculated on a dry basis is close to $58 \%$ of the initial dry matter. Compared to the $69 \%$ of whole volatile fraction, this low temperature treatment gives up to a total conversion of $84 \%$ of the organic matter.

\subsection{Reliability of the results}

The exploitation of the spectra was made on five zones according to the TG curve, which allowed the identification of components. Once the pure variables have been selected, data sets can be resolved into pure infrared spectra and their contributions in the original spectra. After the resolution of the pure components spectra, an associated pure contributions matrix is deduced by writing the raw data matrix as the product of the unknown matrix containing the contributions of the pure infrared spectra in the mixture spectra with the normalised matrix containing the pure component infrared spectra previously resolved. So, the concentration profiles were obtained separately. In order to verify the reliability of the concentrations given by SIMPLISMA, the profile of carbon dioxide is rebuilt all along the experiment. The result is given in Fig. 7 in which we can see that the scale of size was respected, even if some shifts could be seen at the borders of the different zones.

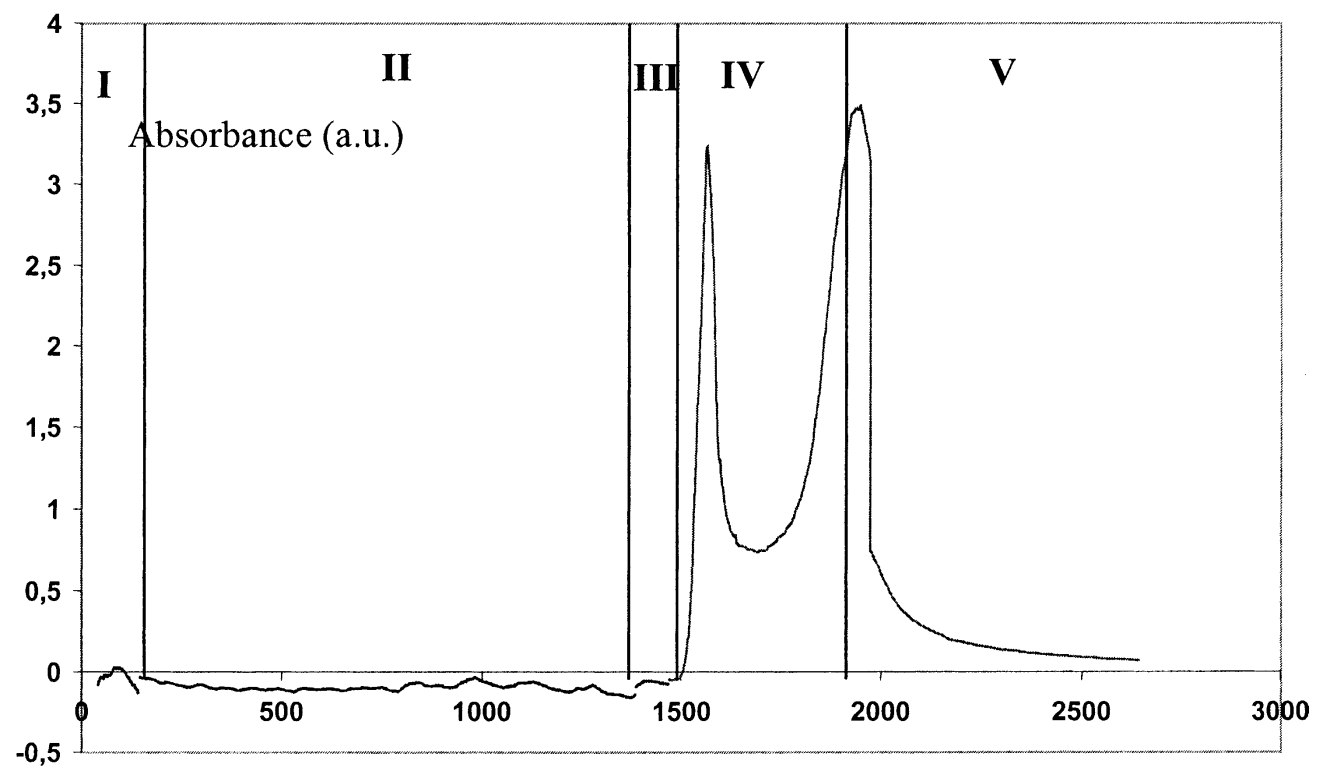

Number of Spectrum

Fig. 7. Reconstruction of the $\mathrm{CO}_{2}$ relative concentration profile on the whole experiment. 


\section{Conclusions}

The TGA-FTIR coupling appears to be a very useful tool to study the thermal decomposition of sewage sludge. Previous results show that the infrared spectra are quite different all along the experiment and that they are characterised by large amount of water and carbon dioxide. But, the complete identification of the lower concentration products needs the use of statistical methods like SIMPLISMA, specially in the zone IV, where up to 11 compounds could be found despite overlapping bands. Long period acquisition has been done with a short time interval between spectra.

The associated concentration profiles obtained led to consider that it is possible to use this experimental set up to study thermal treatment. This study should conduct to the optimisation of the process operating conditions in terms of security and environmental protection.

In addition, at the beginning of the second isothermal stage (at $350^{\circ} \mathrm{C}$ ) a step of combustion was deduced from the identification of the set of $11 \mathrm{com}$ ponents. Also, the determination of the kinetics of sludge decomposition can be envisaged by the use of TGA-FTIR coupling and associated contribution profiles from SIMPLISMA could be helpful.

However, a limitation of this method was illustrated in zone III by the non-justification of close to $35 \%$ of the mass loss. For the moment, this can be interpreted as the production of infrared-spectroscopy inactive species but more analysis must be conducted, perhaps by using a GS or MS apparatus since FTIR does not deteriorate the gas phase. As a matter of fact, chemometric could also be used for those techniques.

\section{Acknowledgements}

The authors thank Drs. W. Windig and J. Guilment for helpful discussions and advice to use SIMPLISMA software. This work was partially supported by the French "Region Midi-Pyrénées".

\section{Appendix A. Theory of the SIMPLISMA mathematical treatment}

As explained before, the SIMPLISMA approach is based on the concept of pure variables. A pure variable is a variable that has intensity contributions from only one of the components of the mixture; in mathematical terms it is a variable with the maximum ratio of the standard deviation to the mean. This ratio is called the purity ratio and is given by the expression:

$P_{i j}=W_{i j} \times\left(\frac{\sigma_{i}}{\mu_{i}+\alpha}\right)$

In this equation, $P_{i j}$ is the purity value of the variable ( $i$ is the variable index), from which the $j$ th pure variable will be selected and represent the mean and the standard deviation of the variable $i$. The constant $\alpha$ is added to give pure variables with a low mean value (i.e. in the noise range) a lower purity value $P_{i j}$ and is called offset. Typical values for $\alpha$ range from 1 to $5 \%$ of the maximum of $\mu_{i}$ The weight factor $W_{i j}$ is a determinant-based function that corrects for previously chosen pure variables. The value of $W_{i j}$ also depends on the value of $\alpha$. The purity values are represented in the form of spectra. Along with the purity spectrum, the standard deviation spectrum is available, described by Eq. (A.2):

$S_{i j}=W_{i j} \times \sigma_{i}$

This spectrum has more similarities with the original spectrum and is used to facilitate the validation of the pure variables. The interactive process makes it possible to guide the pure variable selection by changing the value of $\alpha$ in combination with the option to exclude certain spectral ranges for the selection of pure variables. This capability is especially useful since pure variables may describe unwanted features in the data set.

Once the pure variables have been determined, the data set can be resolved into the pure components and their contributions in the original spectra. The task of the mixture analysis is to express the dataset as a product of a matrix containing the concentrations and a matrix containing the spectra of the pure components:

$D=C R$

$D$ is the matrix with the original data; its size is $c v$, where $c$ is the number of cases (spectra) and $v$ the number of variables (wavelength). The matrix $C$ (size $c n$, where $n$ is the number of pure components) contains the concentration of the pure components in the mixtures. The matrix $R$ (size $n v$ ) contains the resolved spectra. 
Because pure variables are directly proportional to the concentrations of the pure components, their intensities can be used in the matrix $C$, and since the matrix $D$ is known, the matrix $R$ of the pure components can be calculated. Although the pure variable intensities can be used directly (after a normalisation step) to calculate the concentrations, it is better to use the newly calculated $R$ in combination with $D$ to calculate $C$. The thus, obtained concentrations are in fact a projection of the second derivative of the pure variable intensities on the original data set. For details about the procedure to calculate the spectra and concentrations see [13], for comparison of SIMPLISMA with other principal component analysis methods, see [17].

\section{References}

[1] J.E. Hall, Chem. Indus. 6 (1993) 188.

[2] A. Midilli, M. Dogrout, C. Howarth, M. Ling, T. Ayhan, Energy Conv. Manage. 42 (2000) 157.

[3] A. Napoli, Ph.D. Thesis, Université Paul Sabatier de Toulouse, France, 1998.

[4] T. Lupascu, I. Dranca, V.T. Popa, M. Vass, J. Thermal Anal. Calorim. 63 (2001) 855.

[5] R. Font, A. Fullana, J.A. Conesa, F. Llavador, J. Anal. Appl. Pyrolysis 58-59 (2001) 927.

[6] W.M. Groenewoud, W. de Jong, Thermochim. Acta 286 (1996) 341.
[7] P. Antonetti, Ph.D. Thesis, Université de Provence, France, 1999.

[8] C.A. Wilkie, Polym. Degrad. Stab. 66 (1999) 301.

[9] W. Geyer, F.A.-H. Hemidi, L. Brüggemann, G. Hanschmann, Thermochim. Acta 361 (2000) 139.

[10] M. Wesolowski, M. Czerwonka, P. Koniezynski, Thermochim. Acta 323 (1998) 159.

[11] J.P. Gibert, J.-M. Lopez Cuesta, A. Bergeret, A. Crespy, Polym. Degrad. Stab. 67 (2000) 437.

[12] G.R. Saade, J.A. Kozinski, Biomass Bioenergy 18 (2000) 391.

[13] W. Windig, G. Guilment, Anal. Chem. 63 (1991) 1425.

[14] C. Couturier, S. Berger, I. Meiffreu (Eds.), Agence de l'eau Audur-Garonne et Solagro, 2001.

[15] Handbook of Thermal Analysis and Calorimetry, Elsevier, Amsterdam, 1998.

[16] W. Wendlandt, Thermal Analysis, third ed., Wiley, 1985.

[17] W. Windig, J.L. Lippert, M.J. Robbins, K.R. Kresinske, J.P. Twist, A.P. Snyder, Chemometr. Intell. Lab. Sys. 9 (1990) 7.

[18] V. Vacque, N. Dupuy, B. Sombret, J.P. Huvenne, P. Legrand, Appl. Spectrosc. 51 (1997) 407.

[19] W. Windig, D.A. Stephenson, Anal. Chem. 64 (1992) 2735.

[20] W. Windig, W.F. Smith, W.F. Nichols, Anal. Chim. Acta 446 (2001) 467.

[21] P.J. Gemperline, J. Chemometr. 3 (1989) 549.

[22] J.C. Hamilton, P.J. Gemperline, J. Chemometr. 4 (1990) 1.

[23] W. Windig, Chem. Int. Lab. Sys. 4 (1998) 201.

[24] L.A. Currie, L.J. Gleser, Chem. Int. Lab. Sys. 10 (1991) 59.

[25] J.A. Conesa, A. Marcilla, R. Moral, J. Moreno-Caselles, A. Perez-Espinoza, Thermochim. Acta 313 (1998) 63.

[26] T. Shimanouchi, Tables of Molecular National Bureau of Standards, 1972, pp. 1-160.

[27] Data from NIST Standard Reference Database 69, NIST Chemistry WebBook, February 2000 Release, 2000. 